\title{
Transradial approach for mechanical thrombectomy in anterior circulation large-vessel occlusion
}

\author{
Samir Sur, MD, Brian Snelling, MD, Priyank Khandelwal, MD, Justin M. Caplan, MD, \\ Eric C. Peterson, MD, Robert M. Starke, MD, and Dileep R. Yavagal, MD
}

Department of Neurological Surgery, University of Miami Miller School of Medicine, Miami, Florida

\begin{abstract}
OBJECTIVE The goals of this study were to describe the authors' recent institutional experience with the transradial approach to anterior circulation large-vessel occlusions (LVOs) in acute ischemic stroke patients and to report its technical feasibility.
\end{abstract}

METHODS The authors reviewed their institutional database to identify patients who underwent mechanical thrombectomy via a transradial approach over the 2 previous years, encompassing their experience using modern techniques including stent retrievers.

RESULTS Eleven patients were identified. In $8(72 \%)$ of these patients the right radial artery was chosen as the primary access site. In the remaining patients, transfemoral access was initially attempted. Revascularization (modified Treatment in Cerebral Ischemia [mTICl] score $\geq 2 b$ ) was achieved in $10(91 \%)$ of 11 cases. The average time to first pass with the stent retriever was 64 minutes. No access-related complications occurred.

CONCLUSIONS Transradial access for mechanical thrombectomy in anterior circulation LVOs is safe and feasible. Further comparative studies are needed to determine criteria for selecting the transradial approach in this setting.

https://thejns.org/doi/abs/10.3171/2017.1.FOCUS16525

KEY WORDS transradial; thrombectomy; endovascular therapy; EVT; acute ischemic stroke; AIS; large-vessel occlusion

$\mathrm{E}$ NDOVASCULAR treatment for acute large-vessel occlusion (LVO), often via use of stent retriever technology, has become standard treatment for appropriately selected patients, and time to revascularization has a major impact on outcomes. ${ }^{4,8}$ Several factors, including vascular anatomy, peripheral vascular disease, and body habitus, can complicate or even preclude a traditional transfemoral approach. In these emergency situations, the ability to gain vascular access and optimize delivery of thrombectomy devices to the face of the clot is of paramount importance. ${ }^{14}$

Direct cervical carotid artery puncture, transbrachial, and transradial approaches have been described in this setting, but previous reports have typically focused on these nontraditional approaches as rescue measures after failed transfemoral attempts. ${ }^{5,6,13,16}$ Further, experience with the transradial approach is often confined to posterior circulation access, and this approach with use of modern stent retriever technology has yet to be reported.

At our institution, we have increasingly employed a transradial technique to access both anterior and posterior circulation LVOs, often as our initial approach, to achieve revascularization. Here we report our recent experience with stent retriever mechanical thrombectomy in patients with anterior circulation LVOs performed via a transradial approach.

\section{Methods}

We reviewed our institutional database of cases involving patients undergoing endovascular therapy for acute ischemic stroke (AIS) to identify patients in whom a transradial approach was performed between December 2014 and November 2016. Cases of anterior circulation LVOs were included for analysis. Local institutional review board approval was obtained to review our database for the purpose of this study.

\section{Technique}

Our institutional protocol is to perform endovascular therapy for acute ischemic stroke in awake patients with

ABBREVIATIONS CCA = common carotid artery; ICA = internal carotid artery; LVO = large-vessel occlusion; $\mathrm{mTICI}=$ modified Treatment in Cerebral Ischemia. SUBMITTED December 5, 2016. ACCEPTED January 25, 2017.

INCLUDE WHEN CITING DOI: 10.3171/2017.1.FOCUS16525. 
use of intravenous conscious sedation. General anesthesia is reserved for patients with airway compromise, severe medical comorbidities threatening cardiopulmonary stability, or, in rare cases, extremely agitated patients. All procedures in which radial artery access was used were performed in awake patients.

A transradial approach was selected in 2 situations: 1) as primary access in cases that were expected to be more difficult via the standard transfemoral approach, or 2) in cases in which common femoral artery access had been attempted and the attempt had resulted in failure. In the first scenario, the decision to attempt radial artery access was made based on CT angiography findings or suspicion of tortuous anatomy and unfavorable aortic arch type based on patient age and/or body habitus (Fig. 1). In the remaining cases, preexisting peripheral arterial disease or difficulty navigating the guide catheter into the parent vessel from the aortic arch led to an intraoperative decision to convert to radial access.

When a transradial approach is selected, we always use the right radial artery. Use of the right radial artery, rather than the left, allows for easier navigation of guide catheters into the common and internal carotid arteries, and it also allows us to maintain our standard setup for transfemoral access. In our standard biplane angiography suite, the patient's right arm is placed alongside the body in such a manner that the right radial artery access site is very close to the right common femoral artery access site.

Prior to radial artery puncture, Barbeau testing is performed to determine adequacy of the ulnar collateral circulation to the hand by occluding the radial artery and observing the plethysmograph wave form and pulse oximetry measurement from the thumb. ${ }^{1}$ The radial artery area is prepared and draped at the patient's side to minimize any difference from our standard setup for femoral
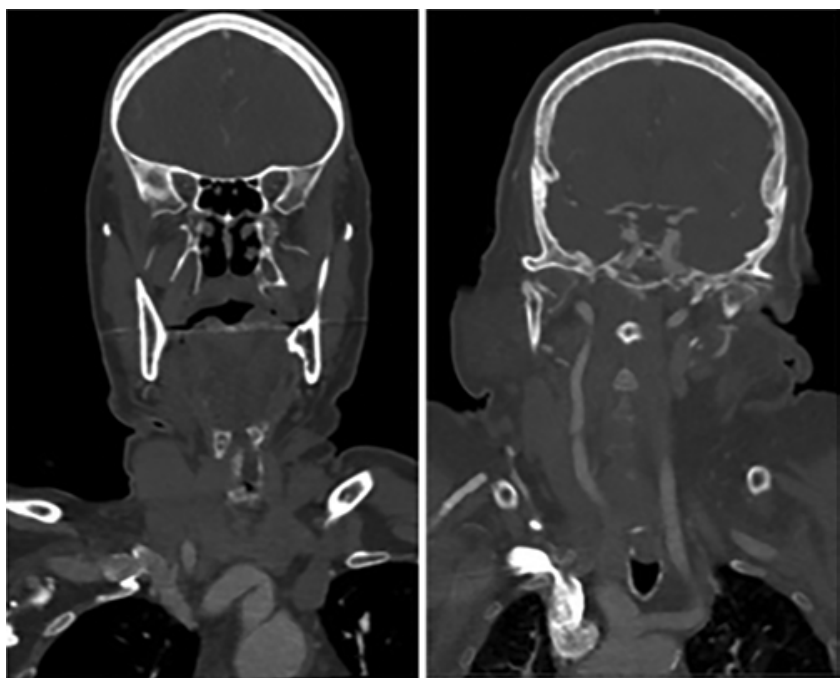

FIG. 1. Left: CT angiogram demonstrating a Type III aortic arch and tortuous innominate artery. In this scenario, transradial catheterization of the right carotid artery avoids navigation of the aortic arch and proximal innominate folds. Right: CT angiogram demonstrating a Type II aortic arch and "bovine" configuration of the left common carotid origin. A transradial approach affords a relatively direct path to the left CCA from the right subclavian artery. artery access with respect to workflow and catheter work. The periarterial tissue is infiltrated with lidocaine, and the radial artery is cannulated using a 20 -gauge needle with single- or double-wall technique according to operator preference. We typically do not use ultrasound guidance for our initial radial artery cannulation unless the pulse is difficult to palpate. A 6-Fr Glidesheath introducer sheath is then placed over a 0.025 -inch hydrophilic guidewire (Terumo Medical). A radial artery angiogram is performed through the sheath to include a view of the brachial bifurcation, and antispasmodic agents (verapamil 2.5 $\mathrm{mg}$ and nitroglycerine $200 \mu \mathrm{g}$ ) are administered through the sheath prior to introduction of the guide catheter.

A 5-Fr Glidecath catheter (Terumo Medical) is then typically navigated into the ipsilateral internal carotid artery (ICA). In cases of left anterior circulation thrombus and a "nonbovine" configuration of the left common carotid artery (CCA) origin, it is often necessary to form a Simmons-2 curve with the diagnostic catheter to allow for placement of the guidewire into the ICA. An exchangelength hydrophilic guidewire is used to allow for rapid placement of the guide catheter into the correct ICA. We typically use a 6-Fr Envoy guide catheter (Codman Neuro) for our transradial thrombectomy cases.

Once the guide catheter is in place, standard technique for thrombectomy is performed, including stent retriever deployment with aspiration through the guide. A representative case demonstrating our technique is shown in Fig. 2.

At the end of the procedure, arteriotomy closure is achieved by compressing the radial artery by use of a

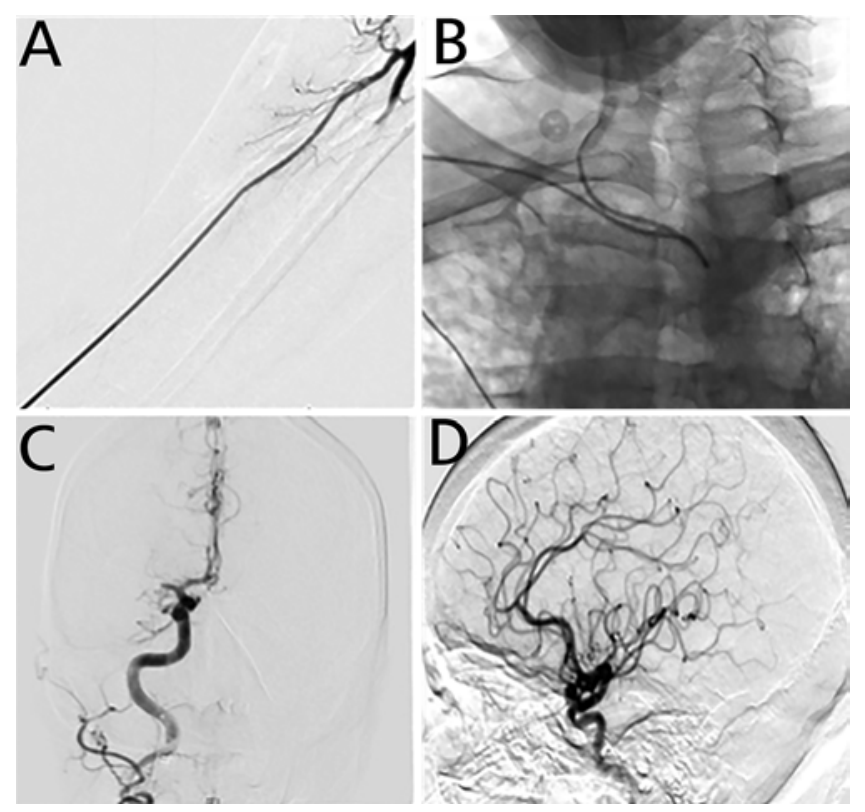

FIG. 2. A: Digital subtraction angiogram (anteroposterior $[A P]$ view) of the radial artery obtained after contrast injection through the 6-Fr vascular sheath. B: Fluoroscopic image (AP view) of the chest obtained after catheterization of the right CCA using a Simmons-2 catheter. C: Digital subtraction angiogram of the right CCA (AP view) showing complete occlusion of the right middle cerebral artery (MCA). D: Digital subtraction angiogram of the right CCA (lateral view) after mechanical thrombectomy showing complete revascularization of the MCA ( $\mathrm{mTICI}$ Score 3). 
transradial band inflated to a pressure to allow patent hemostasis.

\section{Results}

Eleven patients were identified who underwent a transradial approach for mechanical thrombectomy for anterior circulation occlusions. In 8 patients $(72 \%)$, the transradial approach was selected as the primary access. In the remaining patients, femoral artery access was attempted initially. The average patient age in our cohort was 86 years and 5 patients $(45 \%)$ were nonagenarians. The average time from the start of the procedure to the first pass with the stent retriever was 58 minutes. Modified Treatment in Cerebral Ischemia (mTICI) scores of 3 were achieved in 6 cases $(54 \%) .{ }^{17}$ The results are summarized in Table 1. There were no complications associated with radial artery access.

\section{Discussion}

The modern era of endovascular treatment for LVO in patients with acute ischemic stroke has begun with a clear priority on minimizing time to revascularization. To achieve rapid revascularization in aging patients who often harbor challenging vascular anatomy, facility with various access techniques is of the highest importance. Even in anterior circulation LVOs, many cases can be expedited by using a right radial artery approach, which avoids navigating relatively large guide catheters over tortuous and folded aortic arches. Inability to catheterize the necessary craniocervical vessels via a femoral artery approach has been reported in up to $5 \%$ of cases..$^{14}$

Transradial percutaneous coronary intervention was introduced over 30 years ago and has become an increasingly popular technique in the field of interventional cardiology. ${ }^{2}$ The radial artery approach has more recently been applied to neuroendovascular techniques, including diagnostic angiography, carotid artery stent placement, coil embolization of aneurysms, and most recently intervention for acute ischemic stroke..$^{3,5,9-11}$ Broadening indications for endovascular intervention for acute ischemic stroke can only be expected to increase the use of this approach moving forward.

In addition to providing access in cases in which transfemoral techniques are not feasible, a major benefit of the transradial approach is a reduction in complications associated with closure, such as hematoma and pseudoaneurysm formation. ${ }^{7}$ The radial artery is an easily compressible site, and clinically significant hematoma is an extremely rare complication in a transradial approach; in contrast, brachial and direct carotid puncture approaches incur a substantial risk of hemorrhage, and closure options for these approaches are not ideal.,13,16 Furthermore, inadvertent occlusion of the radial artery is unlikely to result in clinical symptoms, given the typically robust collateral supply to the hand from the ulnar and interosseous branches. ${ }^{15}$

Limitations of the transradial approach include 1) the need to accumulate experience with it to facilitate navigating the guide catheter into a "nonbovine" variant left carotid artery, and 2) constraints on catheter size. ${ }^{12}$ Although
TABLE 1. Clinical and demographic characteristics of 11 patients who underwent mechanical thrombectomy via a transradial approach

\begin{tabular}{|c|c|c|c|c|c|c|c|}
\hline \multirow[b]{2}{*}{$\begin{array}{l}\text { Case } \\
\text { No. }\end{array}$} & \multirow{2}{*}{$\begin{array}{l}\text { Age } \\
\text { (yrs), } \\
\text { Sex }\end{array}$} & \multirow[b]{2}{*}{$\begin{array}{l}\text { IV } \\
\text { tPA }\end{array}$} & \multicolumn{2}{|c|}{$\begin{array}{l}\text { NIHSS } \\
\text { Score }\end{array}$} & \multirow[b]{2}{*}{$\begin{array}{c}\text { Clot } \\
\text { Location }\end{array}$} & \multirow{2}{*}{$\begin{array}{c}\text { Time from } \\
\text { AA to } \\
\text { 1st Pass } \\
\text { (mins) } \dagger\end{array}$} & \multirow[b]{2}{*}{$\begin{array}{l}\text { mTICl } \\
\text { Score }\end{array}$} \\
\hline & & & Initial $^{*}$ & Discharge & & & \\
\hline 1 & $90, F$ & Yes & 18 & 0 & Lt $\mathrm{M}_{1}$ & 76 & 3 \\
\hline 2 & $89, F$ & No & 8 & 18 & Rt M & 61 & $2 b$ \\
\hline 3 & $86, M$ & Yes & 18 & 19 & Rt $M_{1}$ & 29 & 3 \\
\hline 4 & $75, F$ & Yes & 20 & 20 & Rt $M_{1}$ & 69 & 3 \\
\hline 5 & $91, F$ & Yes & 12 & 3 & Rt ICA T & 23 & 3 \\
\hline 6 & $91, \mathrm{M}$ & Yes & 25 & 10 & Lt $\mathrm{M}_{1}$ & - & 3 \\
\hline 7 & $65, M$ & Yes & 3 & 1 & Rt $M_{1}$ & 65 & $2 b$ \\
\hline 8 & $95, F$ & No & $>20$ & $>20$ & Rt M & 55 & $2 b$ \\
\hline 9 & $83, M$ & Yes & 15 & 5 & Rt M 2 & 85 & 3 \\
\hline 10 & $95, M$ & No & 1 & 20 & Lt M & - & $2 a$ \\
\hline 11 & $85, F$ & Yes & 24 & 11 & Lt M & 48 & $2 b$ \\
\hline
\end{tabular}

$A A=$ arterial access; IV = intravenous; $M_{1}=M_{1}$ segment of middle cerebral artery (MCA); $M_{2}=M_{2}$ segment of MCA; NIHSS = National Institutes of Health Stroke Scale; $\mathrm{T}=$ terminus; $\mathrm{tPA}=$ tissue plasminogen activator.

* At presentation.

† Procedural times for Cases 6 and 10 were not recorded.

carotid artery stenting has been described via a transradial approach, we prefer to place a short 6 -Fr vascular sheath, which does not cause significant damage to the distal upper-extremity vasculature in our experience. This sheath does limit the ability to use larger catheters, such as older balloon guide catheters, and quadraxial systems in cases that may require advanced catheter support. However, larger systems have been used in a transradial technique and new catheters and devices are emerging that can improve therapeutic options.

Despite these limitations, our recent experience demonstrates that technical success is readily achievable $(54 \%$ mTICI 3, 36\% mTICI $2 b$ ) in a relatively expedited fashion (deployment of stent retriever in under an hour). Further, despite the lack of ability to employ balloon guide catheters in this case series, we did not experience any distal embolizations during attempted thrombectomy. Certainly with more experience and the introduction of 6-Fr balloon guide catheters, we expect procedural times to decrease; however, given the patient population (average age 86 years) we believe these times represent a comparable performance. We anticipate employing this approach in an increasing proportion of our ischemic stroke patients as we define and identify the factors predictive of difficulty or failure with a transfemoral approach.

\section{Conclusions}

Transradial access for mechanical thrombectomy in patients with anterior circulation LVOs is feasible and has been used increasingly frequently at our institution. Further studies are necessary to compare efficacy with the traditional transfemoral approach and to delineate the criteria by which the transradial approach should be primarily selected in patients with acute ischemic stroke. 


\section{References}

1. Barbeau GR, Arsenault F, Dugas L, Simard S, Larivière MM: Evaluation of the ulnopalmar arterial arches with pulse oximetry and plethysmography: comparison with the Allen's test in 1010 patients. Am Heart J 147:489-493, 2004

2. Campeau L: Percutaneous radial artery approach for coronary angiography. Cathet Cardiovasc Diagn 16:3-7, 1989

3. Castriota F, Cremonesi A, Cobalto A: [Angioplasty with stent positioning at the level of the carotid bifurcation and dilatation with the kissing balloon technique between the origin of the internal and external carotid arteries. Report of a case.]

Radiol Med (Torino) 97:543-546, 1999 (Ital)

4. Goyal M, Demchuk AM, Menon BK, Eesa M, Rempel JL, Thornton J, et al: Randomized assessment of rapid endovascular treatment of ischemic stroke. N Engl J Med 372:10191030,2015

5. Haussen DC, Nogueira RG, DeSousa KG, Pafford RN, Janjua N, Ramdas KN, et al: Transradial access in acute ischemic stroke intervention. J Neurointerv Surg 8:247-250, 2016

6. Jadhav AP, Ribo M, Grandhi R, Linares G, Aghaebrahim A, Jovin TG, et al: Transcervical access in acute ischemic stroke. J Neurointerv Surg 6:652-657, 2014

7. Jolly SS, Yusuf S, Cairns J, Niemelä K, Xavier D, Widimsky $\mathrm{P}$, et al: Radial versus femoral access for coronary angiography and intervention in patients with acute coronary syndromes (RIVAL): a randomised, parallel group, multicentre trial. Lancet 377:1409-1420, 2011

8. Khandelwal P, Yavagal DR, Sacco RL: Acute ischemic stroke intervention. J Am Coll Cardiol 67:2631-2644, 2016

9. Lawson MF, Velat GJ, Fargen KM, Hoh BL, Mocco J: Direct radial artery access with the 070 neuron guide catheter for aneurysm coiling: a novel application of the neuron catheter for cerebral interventions. Neurosurgery 71 ( 2 Suppl Operative):onsE329-onsE334, 2012

10. Levy EI, Kim SH, Bendok BR, Qureshi AI, Guterman LR, Hopkins LN: Transradial stenting of the cervical internal carotid artery: technical case report. Neurosurgery 53:448452, 2003

11. Matsumoto Y, Hokama M, Nagashima H, Orz Y, Toriyama T, Hongo K, et al: Transradial approach for selective cerebral angiography: technical note. Neurol Res 22:605-608, 2000

12. Mendiz OA, Sampaolesi AH, Londero HF, Fava CM, Lev GA, Valdivieso LR: Initial experience with transradial ac- cess for carotid artery stenting. Vasc Endovascular Surg 45:499-503, 2011

13. Mokin M, Snyder KV, Levy EI, Hopkins LN, Siddiqui AH: Direct carotid artery puncture access for endovascular treatment of acute ischemic stroke: technical aspects, advantages, and limitations. J Neurointerv Surg 7:108-113, 2015

14. Ribo M, Flores A, Rubiera M, Pagola J, Mendonca N, Rodriguez-Luna D, et al: Difficult catheter access to the occluded vessel during endovascular treatment of acute ischemic stroke is associated with worse clinical outcome. J Neurointerv Surg 5 (Suppl 1):i70-i73, 2013

15. Ruengsakulrach P, Eizenberg N, Fahrer C, Fahrer M, Buxton BF: Surgical implications of variations in hand collateral circulation: anatomy revisited. J Thorac Cardiovasc Surg 122: $682-686,2001$

16. Wu CJ, Cheng CI, Hung WC, Fang CY, Yang CH, Chen CJ, et al: Feasibility and safety of transbrachial approach for patients with severe carotid artery stenosis undergoing stenting. Catheter Cardiovasc Interv 67:967-971, 2006

17. Zaidat OO, Yoo AJ, Khatri P, Tomsick TA, von Kummer R, Saver JL, et al: Recommendations on angiographic revascularization grading standards for acute ischemic stroke: a consensus statement. Stroke 44:2650-2663, 2013

\section{Disclosures}

Dr. Yavagal reports a consultant relationship with Medtronic and receipt of clinical or research support from Medtronic, Stryker, and Neuravi.

\section{Author Contributions}

Conception and design: Sur, Khandelwal, Caplan, Peterson, Starke, Yavagal. Acquisition of data: Sur, Khandelwal, Caplan, Starke. Analysis and interpretation of data: Sur, Snelling. Drafting the article: Sur, Khandelwal. Critically revising the article: all authors. Reviewed submitted version of manuscript: Sur, Snelling, Peterson, Starke, Yavagal. Approved the final version of the manuscript on behalf of all authors: Sur. Study supervision: Yavagal.

\section{Correspondence}

Samir Sur, Department of Neurological Surgery, University of Miami Miller School of Medicine, 1095 NW 14th Terrace (D46), Miami, FL 33136. email: samir.sur@jhsmiami.org. 